\title{
On the independence of judged frequencies for items presented in successive lists*
}

\author{
CHARLES S. REICHARDT. JOHN J. SHAUGHNESSY, and JOEL ZIMMERMAN \\ Vorthwestern Universit?, Evanston, Illinois 60201
}

\begin{abstract}
In an experiment examining retroactive interference effects in a frequency-judging task. all Ss were presented with a list of words occurring varying numbers of times according to either a massed- or distributed-practice (IIP or DP) schedule. They were then asked to judge how of ten each word had occurred. Following this. Ss were given one of four types of second tasks: a second list with different items followed by a frequency-judging task for that list (Condition New): a second list with items repeated from the first list but with different frequencies for each item. while either maintaining items as either MP or DP items (Condition Same) or switching MP items to DP. and vice versa (Condition Reverse): followed by a frequency-judging task for the second-list frequencies only: or a puzzle task for the amount of time required for second-list presentation and judgment in the other conditions (Condition None). Finally, all Ss were asked to recall List 1 frequencies. List 2 frequencies were less discriminable in Conditions Same and Reverse than in Condition New. Recall of List 1 frequencies, however. was not different for these three groups, but was poorer than in Condition None. It was concluded that recall of List 1 frequencies was independent of List 2 frequencies. but that List 2 frequency judgments were not independent of List 1 frequencies.
\end{abstract}

One seemingly inevitable consequence of the presentation of an item in an experimental situation is some memorial representation for that item's frequency of occurrence. The discrimination among items having different situational frequencies has been proposed as the theoretical mechanism mediating performance in verbal-discrimination learning (Ekstrand. Wallace, \& Underwood. 1966), as well as in typical recognition experiments (Underwood \& Freund. 1968). Since the frequency attribute has been considered to be of some importance theoretically. investigations concerning frequency judgments per se are of interest. The fact that Ss reliably can judge situational frequency has been firmly established (Hintzman. 1969; Underwood. Zimmerman. \& Freund. 1971). The discriminability of items having different situational frequencies decreases over time (U'nderwood. Zimmerman. \& Freund. 1971). Distortions in the judged frequency of an item also have been found when items associatively related to it have been presented in the same list (Leicht. 1968: Shaughnessy \& Underwood. 1973). In spite of the fact that experimental situations can be found in which $S_{s}{ }^{\circ}$ judgments of frequency do not reflect accurately actual presented frequency. it is generally the case that when Ss are presented with lists of unrelated items and tested immediately. their abilities to judge situational frequencies are quite good.

The present experiment examined the problem of the relative independence of two different situational frequencies for the same item. This issue is related to interpretations which have been put forth to account for performance in verbal-discrimination transfer tasks in

*The authors wish to thank Dr. Benton J. Lnderwood for his helpful advice. which those items which were correct in each pair become the incorrect members of each pair and the incorrect items become the correct members of each pair. Generally, performance in these tasks does not deteriorate to a chance level as would be predicted from a strict interpretation of frequency theory. Underwood. Shaughnessy, and Zimmerman (1972) suggested that these findings could be understood if one assumed that the frequencies accrued by an item during original learning and transfer were independent.

The possible independence of situational frequencies was proposed first by Hintzman and Block (1971). They hypothesized that repetitions of an item established multiple traces for that item. This multiple-trace hypothesis has been characterized in the following manner: each repetition of an event establishes its own trace: each trace coexists with traces of other repetitions of the event. and each trace is identifiable by a time tag. As a test of this hypothesis. they presented Ss with two successive lists of words (separated by a 5 -min filled interval). following which they asked the Ss to judge the frequency of occurrence of each item in each list separately. Items were presented 0.2 . or 5 times in List 1 and 0 . 2. or 5 times in List 2. The judged frequencies of items from a given list were determined primarily by the presented frequencies of those items in that list. and they were influenced considerably less (but to a statistically significant extent) by the presented frequencies of those items in the other list. On the basis of these findings. Hintzman and Block concluded that items can have multiple independent situational frequencies which are differentiated via time tags.

Hintzman and Block imply that the time tagging of frequencies is important in the $S^{\circ}$ abilities or differentiate situationa! frequencies. In their stud. Ss 
judged frequencies of items presented in two lists separated by a 5 -min filled interval. Returning to a consideration of verbal-discrimination transfer tasks, however, it has not been the case that the two lists in these experiments (e.g., Underwood et al, 1972) have been separated by any more of an interval than was necessary to read instructions to the $S$ and to effect the mechanics of the transfer from the first to the second list. It remains an important theoretical question, then, whether Ss can maintain multiple independent situational frequencies for items presented in two minimally separated lists. The present experiment can be viewed as a test of this question.

Basically, the present study was intended to examine retroactive interference effects in a frequency-judging task. All Ss were presented with a first list in which words were presented varying numbers of times. Following list presentation, they were asked to judge how many times each item had occurred. Then, each of three groups of Ss was presented immediately with one of three types of second lists. For one group, none of the to-be-judged words in the second list had occurred in the first list (Condition New). The other two groups received lists in which items were repeated from the first list, with all to-be-judged items being presented with frequencies other than those with which they had appeared in the first list. The differentiation between these two groups requires a further elaboration of the nature of the lists. Hintzman and Block (1970) found that the frequency attribute was independent of the at tribute specifying how a given item had been presented (i.e., either in a massed or distributed fashion). It is possible that if frequencies for a given item can be differentiated on the basis of time tags, they might also be differentiated on the basis of the way in which the item was presented. To study this problem, one group of Ss was given a second list in which the items from the first list were used again; if an item had been presented in a massed fashion in the first list, it was presented in the same way in the second list. Distributed items were treated in a similar manner (Condition Same). For the second group of Ss having the same items in the two lists, if an item was massed in the first list, it was distributed in the second, and vice versa (Condition Reverse). If the mode of presentation of an item exerts an influence on the degree of independence of frequencies for a given item, then the second-list frequencies should be more discriminable from each other in Condition Reverse relative to Condition Same. Following second-list presentation, Ss were asked to judge the frequencies with which items had occurred only in the second list. Immediately after this judgment task, Ss were asked to recall the frequencies with which items had occurred in the first list. Finally, to assess the effects of not having had any second list at all, a fourth group of Ss (Condition None) was given a puzzle task for the amount of time required by other $\mathrm{Ss}$ for presentation and frequency judging of the second list and then was asked to recall the frequencies of the first-list items (the only list they had seen).

Assuming that Ss can establish independent multiple traces of events, by time tagging or any other mechanism, then the predictions of the multiple-trace hypothesis for the present manipulations would be relatively straightforward. First, the degree of discrimination among second-list frequencies should be no different for lists in which items are repeated from the first list than for those in which new items are presented. Also, recall of the first-list frequencies should be no different for the groups having varying types of second lists. In any case, any interdependence in judged frequencies for items presented in both lists can be taken as evidence against the notion of independent multiple representations of item frequencies.

\section{METHOD}

\section{Lists}

Four different lists were required, one for List 1 and one for each of the List 2 conditions-Same, Reverse, and New. Within each list there were three instances of each of eight types of items. These eight types of items were the result of the factorial combination of presentation frequencies of $1,4,7$, or 10 with either a massed-presentation (MP) or distributed-presentation (DP) schedule. Assignment to MP or DP was done for items presented only once, though the MP-DP distinction for these items remains only a nominal one. Each list was divided into thirds, and one item of each type was assigned to each third. A total of 24 words was chosen randomly from a previously selected systematic sample of two-syllable words having a Thorndike-Lorge frequency of from 1 to 10 . These to-be-judged words were used to construct List 1 . For List 2 of Condition New, 24 additional words were selected randomly from the same source. For List 2 of Condition Same, the List 1 words were used again with items being assigned to frequencies other than those with which they were presented in List 1 , and subject to the restriction that the three items having a given presentation frequency in List 2 be composed of items having had one of each of the other three presentation frequencies in List 1. For example, of the three items presented once in List 2 , one would have occurred 4 times in List 1 , one 7 times, and one 10 times; of the three items presented 10 times in List 2, one would have occurred once in List 1 , one 4 times, and one 7 times. For Condition Same, this reassignment of frequency was done separately for MP and DP items. In addition, a given item always appeared in the same third of the list in both Lists 1 and 2. List 2 for Condition Reverse involved the same restrictions as in Condition Same for the reassignment of items to different frequencies, but this time MP items were assigned to DP schedules, and vice versa. For both Lists 1 and 2, five words were presented one time each at the beginning of the list and five different words were presented one time each at the end of the list. The same 10 words were used for this purpose in List 1 and all three second lists, though their order was changed from List 1 to List 2. None of these words appeared in the frequency-judgment test. The complete lists were each 142 positions in length.

\section{Frequency-Judgment Booklets}

For each list, the 24 to-be-judged words plus 6 words that had not occurred in the study list were presented 1 per page in a 30-page test booklet. The 6 zero-frequency words werc drawn randomly from the same pool as was used for the selection of 
the to-be-judged words. The same 6 zero-frequency words were judged for frequency of occurrence in Lists 1 and 2 and in the final recall of List 1 . The 30 words in each booklet were presented in a different random order for each $S$. No two word orders for the same $S$, nor any two orders presented to different Ss, were the same.

\section{Procedure and Subjects}

Each list was recorded on magnetic tape in a female voice at a 2-sec presentation rate, for a total presentation time of $284 \mathrm{sec}$. Prior to presentation of the first list, Ss were told that they would hear a list of words, some of which would be repeated varying numbers of times. They were told that they would be asked to judge how many times each word had occurred, but that there were too many words for them to try to actually count each occurrence. Rather, they were to try to get a "feel" for how many times each word was presented. Following the presentation of List 1, Ss were given a test booklet and asked to indicate in the blank provided next to each word the number of times they thought the word had occurred. If they thought a word had not been presented in the list, they were to assign that word a zero.

Immediately after the Ss completed the frequency-judging task, averaging about $2 \mathrm{~min}$ after the presentation of the last word of List 1 , those Ss in Conditions New, Same, and Reverse were given instructions appropriate to the second list. All Ss were told that some of the words from the first list would be repeated in the second list, but that they were to judge only the number of times a word occurred in the second list. Following the list presentation, Ss again filled out the test booklets using integer values to represent the items' presentation frequencies. Those Ss in Condition None, instead of hearing a second list, were given a nonverbal (pyramid) puzzle to work on for a period of $8 \mathrm{~min} 45 \mathrm{sec}$, the approximate time taken by Ss in the other conditions for list presentation and the frequency-judging task.

All Ss, following their assigned interpolated task, were given a test booklet and asked again to judge the frequencies with which the items had been presented in List 1 . To minimize the likelihood of Ss' simply trying to recall the number they had assigned a word during the first List 1 judgment task, a different scaling procedure was used for the recall test. The technique chosen was magnitude estimation. The Ss were told to consider the value of 100 to represent a word that had occurred an average number of times in List 1 and to judge the frequencies of other words by expressing them as some ratio of 100 (e.g., if a word occurred twice as often as the average word, it was to be assigned a value of 200). The value of zero was to be used again for those words which had not occurred in List 1 .

A total of $88 \mathrm{Ss}$ was assigned to the four groups according to a block randomized schedule. All Ss were Northwestern University students enrolled in introductory psychology and were serving in the experiment in partial fulfillment of a course requirement.

\section{RESULTS}

\section{List 1 Judgments}

The mean judged frequencies for items of varying presentation frequencies in List 1, summing over the four groups, are presented in Fig. 1. The mean judgment for items not presented (zero-frequency items) was 0.45 , with a range from 0.37 in Condition Reverse to 0.54 in Condition New. For items presented once, the mean judgment was 1.83 , with a range from 1.64 in Conditions New and None to 1.98 in Condition Same. Since there were no drastic differences among the groups

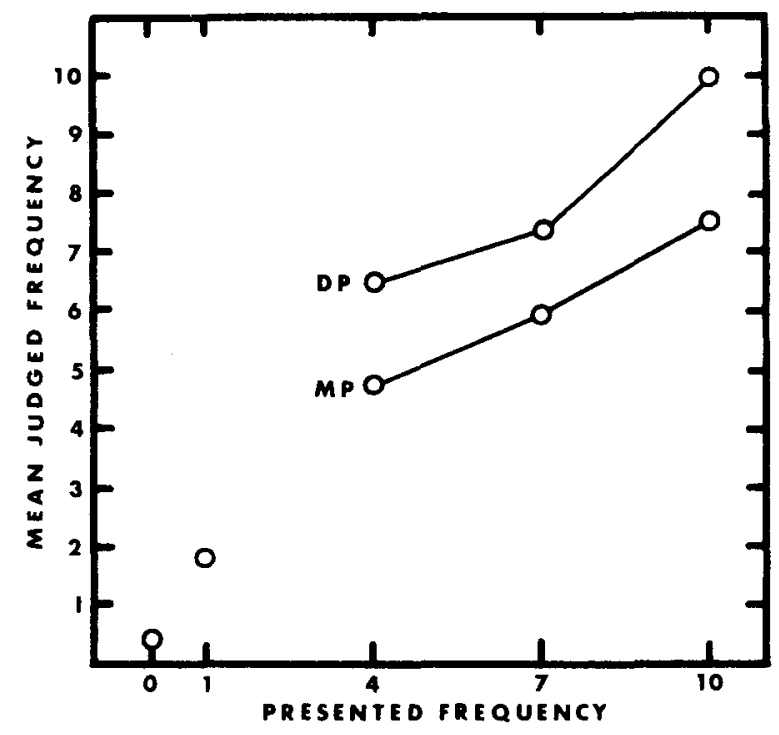

Fig. 1. Mean judged frequencies as a function of presented frequencies for List 1 items.

in their judgments of zero and one items and since the MP.DP variable is meaningful only for items presented more than once, only items presented 4,7 , or 10 times were considered for purposes of statistical analysis. As can be seen in Fig. 1, the mean judged frequency for MP items (6.07) was less than that for DP items (7.92) $[F(1,84)=61.22, p<.01]$. The mean judged frequencies, summing over the MP-DP variable, for items presented 4,7 , and 10 times were 5.60, 6.66, and 8.74 , respectively. This increase in judged frequency as a function of presentation frequency was reliable $[F(2,168)=84.91, p<.01]$. There was no significant difference among the four independent groups nor were there any interactions of groups with the MP-DP or frequency variables (the largest $F$ value for any comparison involving groups was 1.36).

\section{List 2 Judgments}

In order to determine if there was any change in Ss' abilities to discriminate among frequencies even in a list in which a majority of the items were not repeated from a previous list, an analysis comparing frequency judgments in Lists 1 and 2 was made separately for Condition New. The same analysis which was used to compare the four groups in List 1 was used again. The mean judged frequencies and standard deviations for Lists 1 and 2 of Condition New as a function of presentation frequency and the MP-DP variable are presented in Table 1. Overall, the mean judged frequency of items in List 2 (5.91) was less than that in List 1 (6.76) $[F(1,21)=5.04: p<.05]$. Nonetheless. there was no difference between the judgments for the two lists with respect to the effect of either the MP-DP variable or the variable of presentation frequency. 
Table 1

Mean Judged Frequencies for Items in List 1 of Condition New and List 2 of Conditions New, Same, and Reverse

\begin{tabular}{|c|c|c|c|c|c|c|c|c|}
\hline & \multicolumn{4}{|c|}{ Condition New: List 1} & \multicolumn{4}{|c|}{ Condition New: List 2} \\
\hline & 1 & 4 & 7 & 10 & 1 & 4 & 7 & 10 \\
\hline IIP & 1.64 & $\begin{array}{c}4.59 \\
(3.88)\end{array}$ & $\begin{array}{c}5.29 \\
(4.20)\end{array}$ & $\begin{array}{c}7.15 \\
(4.44)\end{array}$ & 2.32 & $\begin{array}{c}3.91 \\
(2.53)\end{array}$ & $\begin{array}{c}4.92 \\
(4.20)\end{array}$ & $\begin{array}{c}5.35 \\
(4.54)\end{array}$ \\
\hline \multirow[t]{2}{*}{$\mathrm{DP}$} & $(2.02)$ & $\begin{array}{c}6.64 \\
(3.76)\end{array}$ & $\begin{array}{c}7.42 \\
(4.37)\end{array}$ & $\begin{array}{c}9.45 \\
(4.71)\end{array}$ & $(2.65)$ & $\begin{array}{c}5.39 \\
(3.46)\end{array}$ & $\begin{array}{c}7.35 \\
(3.82)\end{array}$ & $\begin{array}{c}8.52 \\
(5.42)\end{array}$ \\
\hline & \multicolumn{4}{|c|}{ Condition Same: List 2} & \multicolumn{4}{|c|}{ Condition Reverse: List 2} \\
\hline MP & 6.04 & $\begin{array}{c}5.64 \\
(3.90)\end{array}$ & $\begin{array}{c}6.80 \\
(4.40)\end{array}$ & $\begin{array}{c}6.73 \\
(4.20)\end{array}$ & 5.47 & $\begin{array}{c}6.76 \\
(4.85)\end{array}$ & $\begin{array}{c}7.95 \\
(4.47)\end{array}$ & $\begin{array}{c}7.52 \\
(4.01)\end{array}$ \\
\hline DP & $(4.47)$ & $\begin{array}{c}6.89 \\
(4.78)\end{array}$ & $\begin{array}{c}7.94 \\
(4.49)\end{array}$ & $\begin{array}{c}8.35 \\
(5.39)\end{array}$ & $(3.83)$ & $\begin{array}{c}7.02 \\
(5.26)\end{array}$ & $\begin{array}{c}7.98 \\
(4.41)\end{array}$ & $\begin{array}{c}8.35 \\
(4.52)\end{array}$ \\
\hline
\end{tabular}

Vote-Values in parentheses are standard deviations.

Additionally, the variabilities of the frequency judgments. indexed by the standard deviations. were comparable for the two lists. It appears clear that the degree of discrimination among frequencies was not reduced in List 2 for the group in which to-be-judged items were not repeated from List 1.

The most critical comparison for purposes of evaluating the multiple-trace hypothesis involves those groups in which items were repeated from List 1 (Conditions Same and Reverse) as compared to Condition New, in which no to-be-judged items were carried over from List 1 . The mean judged frequencies in List 2 for Conditions Same and Reverse are presented in Table 1. An analysis, summing over the MP-DP variable in order to allow for the inclusion of items presented

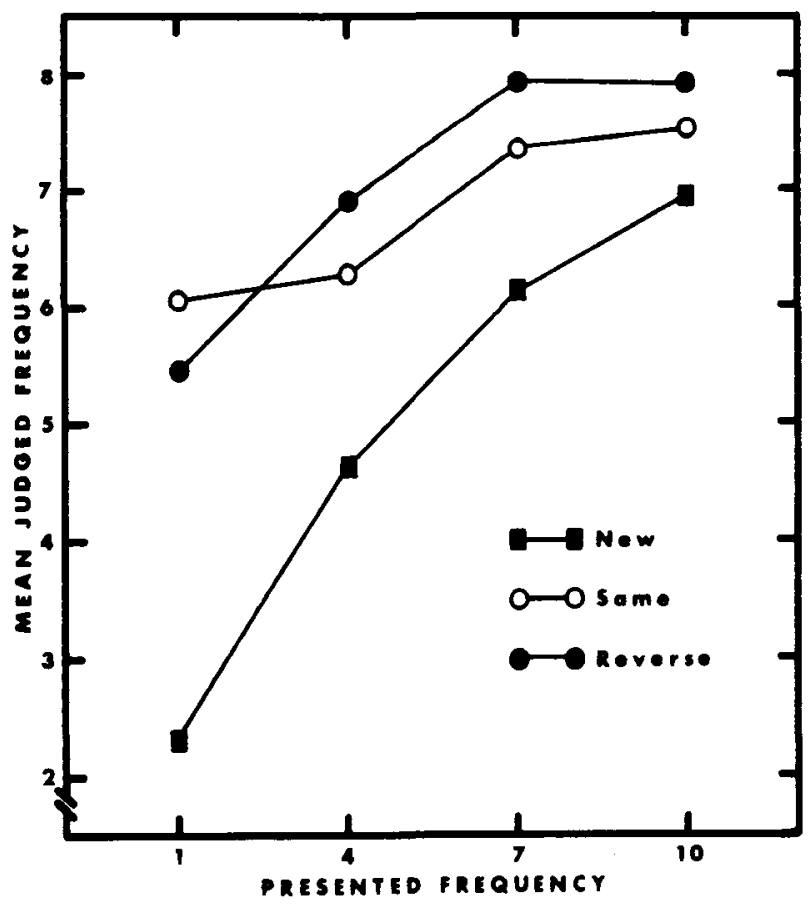

Fig. 2. Mean judged frequencies in List 2 as a function of presented frequencies for Conditions New. Same, and Reverse. once. indicated that the mean judged frequency for items in Condition Same (6.80) was not different from that in Condition Reverse $(7.06) \quad[F(1.63)<1]$. Figure 2 provides a graphical representation of this comparison and other comparisons to follow. The increase in judged frequency as a function of presented frequency did not differ for the two groups $[F(3,189)=$ 1.30. $\mathrm{p}>.05]$. The combined judgments for Conditions Same and Reverse were then compared to those for Condition New. Summing over the four presentation frequencies. the mean judged frequency for items in Conditions Same and Reverse (6.94) was higher than that in Condition New (5.01) $[F(1.63)=10.85$. $p<.01]$. More critically, however, the increase in judged frequency as a function of presented frequency was greater in Condition New than in the combined Conditions Same and Reverse $[F(3.189)=6.71$. $p<.01]$. Thus, frequency discrimination was reduced in those conditions in which to-be-judged items were repeated from the first list relative to a group having a second list in which items were not repeated from the first list.

The question was raised in the introduction as to whether a change from massed presentation in List 1 to distributed presentation in List 2 might serve as a tag allowing for a greater differentiation between the frequencies with which a given item had been presented in the two lists. The failure to find a significant difference in the effect of presented frequency on judged frequency in Condition Same relative to that in Condition Reverse can be taken as evidence against this hypothesis. To determine how discriminable MP and DP items were in the second list for these two conditions, separate analyses were performed. Referring again to Table 1. it can be seen that within Condition Same, MP items were judged to have occurred less frequently than did DP items. The mean judged frequency for MP items was 6.39. while that for DP items was $7.73[\mathrm{~F}(1,21)=$ 8.91. $\mathrm{p}<.011$. This distinction seemed to be lost within Condition Reverse in that the mean judged frequency for MP items was 7.41. while that for DP items was 7.78 
$[F(1,21)=1.15, p>.05]$. In any case. it appears that the presence or absence of this MP-DP difference had little effect on the degree of discrimination among items of varying frequencies.

The mean judged frequency of occurrence in List 2 for the six zero-frequency words was 0.61 and ranged from 0.35 in Condition Reverse to 0.95 in Condition New. The increase over the mean judgment of 0.45 for these items in List 1 was not significant $[F(1.65)=2.24$. $p>.05]$. Additionally, neither the main effect of conditions $[F(2,63)=1.37]$ nor the interaction of Conditions by Lists $[F(2,63)=1.21]$ was significant $(p>.05)$ with respect to judgments of zero-frequency words.

\section{Recall of List 1 Frequencies}

All judgments in the recall test were to be expressed as proportionate values to the average list frequency which was to have been assigned the value of 100 . Over the four conditions of the experiment, the scale value of the mean recalled frequency was 78.48 . The mean judged frequencies (expressed in terms of the magnitude-estimation scale) for the recall of List 1 frequencies are presented in Fig. 3 for the four conditions of the experiment. In order to include the items presented once, values were taken summing over the MP-DP variable. Summing over all four groups, the mean values assigned to items having presentation frequencies of $1,4,7$, and 10 were $35.55 .80 .39,90.88$, and 107.11, respectively. This increase was reliable $[F(3.252)=124.37 . p<.01]$. An analysis comparable to that used for List 2 judgments indicated no difference between the mean scaled value in Conditions Same and Reverse. Nor was there any difference in the effect of presentation frequency on recall for these two conditions.

It will be remembered that List 2 judgments in Conditions Same and Reverse were found to be greater than the judgments in Condition New. In the recall task, however, Ss were instructed to anchor all judgments around a mean, and this may have eliminated any main effects of conditions, which. statistically. proved to be the case. (The largest $F$ for any comparison regarding a main effect of conditions was 1.35.) The critical statistic for evaluating the independence of frequency judging though, is the interaction between Condition New and the combined Conditions Same and Reverse with respect to the levels of presentation frequency. This interaction, significant for List 2 judgments, was not statistically significant for the recall of List 1 frequencies $[F(3.252)$ $=1.30 . \mathrm{p}>.05]$. Thus, while the judgments of List 2 frequencies apparently were influenced by having had the words repeated from List 1 . the recall of frequencies from List 1 was apparently unaffected by whether or not the words were repeated in List 2.

In the analysis of List 1 recall. another comparison can be made between judgments by $S s$ in Condition

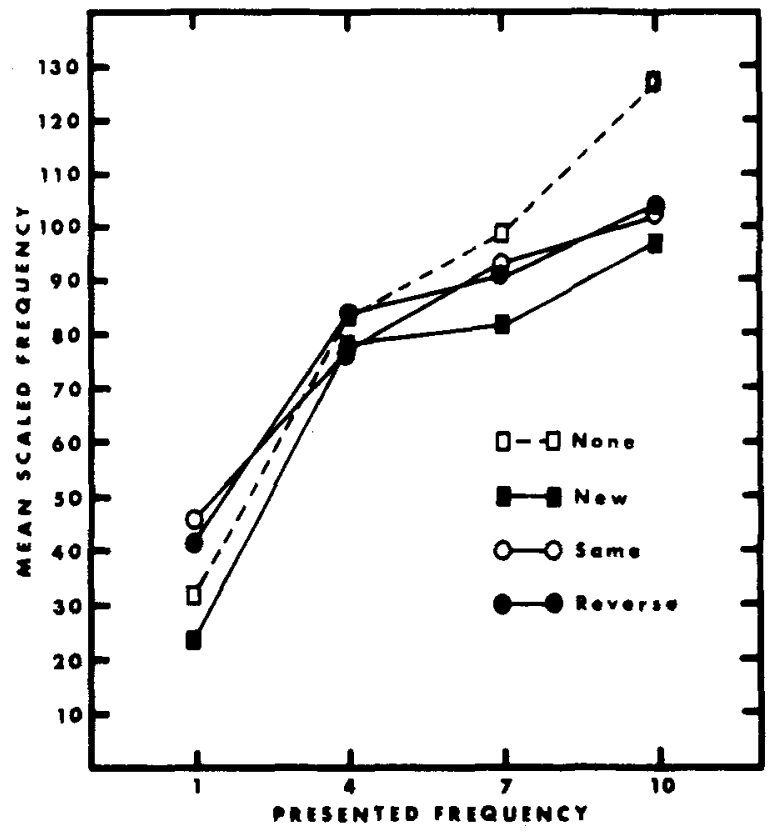

Fig. 3. Recall of List 1 frequencies as a function of presented frequencies for Conditions None, New, Same, and Reverse.

None and those by Ss in the other three conditions combined. Again, although there was no main effect of conditions, there was a significant difference between the discrimination of frequencies in Condition None and the discrimination of frequencies in the other three conditions combined $[\mathrm{F}(3,252)=4.46, \mathrm{p}<.01]$. It may be inferred from these data that $\mathrm{Ss}$ who were given a nonverbal interpolated task were better able to recall differential List 1 frequencies than Ss who received an interpolated frequency-judging task. Furthermore.., the interfering nature of the interpolated task may be considered to be nonspecific to items, since there was no differential loss of discrimination as a function of whether the second list was composed of new items or of items repeated from List 1.

Considering frequencies of only 4.7 , and 10 . the effect of the MP-DP variable can be evaluated. There were no critical predictions made with regard to MP and DP effects in recall. and the data are presented here primarily for the sake of completeness. These results are enumerated in Table 2. Over all four conditions of the experiment, the mean value assigned to MP items was 86.24 and that assigned to DP items was 99.34. and this difference was significant $[F(1.84)=17.44, p<.01]$. The MP-DP difference was not statistically different between Conditions Same and Reverse. but there was less of a difference in these conditions combined than there was in Condition New $[F(1.84)=7.32 . p<.01]$. As had been the case when all four levels of frequency were considered. an analysis over only the highest three levels of frequency resulted in a main effect of frequency $[F(2.168)=28.21 . p<.01]$. as well as an interaction of frequency with the comparison of 
Table 2

Mean Scaled Recall of List 1 Frequencies

\begin{tabular}{|c|c|c|c|c|c|c|c|c|}
\hline & \multicolumn{4}{|c|}{ Condition None } & \multicolumn{4}{|c|}{ Condition New } \\
\hline & 1 & 4 & 7 & 10 & 1 & 4 & 7 & 10 \\
\hline MP & 31.55 & $\begin{array}{c}88.52 \\
(93.21)\end{array}$ & $\begin{array}{c}87.27 \\
(93.10)\end{array}$ & $\begin{array}{c}111.14 \\
(100.88)\end{array}$ & 23.41 & $\begin{array}{c}68.24 \\
(64.27)\end{array}$ & $\begin{array}{c}63.47 \\
(55.94)\end{array}$ & $\begin{array}{c}84.85 \\
(64.07)\end{array}$ \\
\hline \multirow[t]{2}{*}{ DP } & $(38.02)$ & $\begin{array}{c}77.95 \\
(63.12)\end{array}$ & $\begin{array}{l}109.85 \\
(89.45)\end{array}$ & $\begin{array}{l}142.77 \\
(87.97)\end{array}$ & $(30.63)$ & $\begin{array}{c}87.35 \\
(54.56)\end{array}$ & $\begin{array}{l}100.30 \\
(60.54)\end{array}$ & $\begin{array}{c}108.33 \\
(72.09)\end{array}$ \\
\hline & \multicolumn{4}{|c|}{ Condition Same } & \multicolumn{4}{|c|}{ Condition Reverse } \\
\hline MP & 45.96 & $\begin{array}{c}71.52 \\
(66.94)\end{array}$ & $\begin{array}{l}100.47 \\
(72.11)\end{array}$ & $\begin{array}{c}92.12 \\
(62.74)\end{array}$ & 41.28 & $\begin{array}{c}86.09 \\
(64.06)\end{array}$ & $\begin{array}{c}86.05 \\
(70.14)\end{array}$ & $\begin{array}{c}95.18 \\
(76.03)\end{array}$ \\
\hline $\mathrm{DP}$ & $(43.71)$ & $\begin{array}{c}82.70 \\
(54.84)\end{array}$ & $\begin{array}{c}84.62 \\
(57.23) \\
\end{array}$ & $\begin{array}{l}111.06 \\
(57.29)\end{array}$ & $(37.84)$ & $\begin{array}{c}80.79 \\
(57.19) \\
\end{array}$ & $\begin{array}{c}95.00 \\
(72.94)\end{array}$ & $\begin{array}{l}111.39 \\
(57.25)\end{array}$ \\
\hline
\end{tabular}

Vote-I'alues in parentheses are standard deviations.

Condition None vs the combined Conditions Same, Reverse, and New $[F(2,168)=4.03, p<.05]$. The only other significant source of variation in this analysis was the overall MP-DP by Frequency interaction $[F(2,168)=$ $3.88, \mathrm{p}<.05$ ]

Finally. it remains to be noted that the recall of zero-frequency items resulted in a mean scaled value of 16.33. The means for the four conditions ranged from 14.60 in Condition New to 17.54 in Condition Reverse, and there were no significant differences among the values $[F(3,87)<1, p>.05]$.

\section{Correlational Evidence}

To gain additional information concerning the interplay of List 1 judgments, List 2 judgments, and the recall of List 1 judgments, several correlations were computed for items within Conditions Same and Reverse. Within Condition Same, for each of the 12 items assigned to MP functions within List 1, the mean judged frequency across Ss was tabulated. The mean judged frequencies for each of these items in List 2 as well as the mean number of points assigned to each in the recall test were also determined. The same procedure was used to obtain three scores for the 12 items assigned to DP functions in List 1 within Condition Same and within Condition Reverse for the $12 \mathrm{MP}$ items and for the 12 DP items. The correlations to be reported were determined for each of the four 12-item sets and averaged using Fisher's $\mathrm{r}$ to $\mathrm{Z}$ transformation. For purposes of comparison, several correlations were also taken and averaged over the $12 \mathrm{MP}$ and the $12 \mathrm{DP}$ items of Condition New.

First, a determination was made within Conditions Same and Reverse of the average correlation between presented frequencies and judgments of frequencies for List 1 . This correlation, .84 , was comparable to that for Condition New, 87 .

In the conditions wherein items were repeated from List 1. however, the average correlation between presented and judged frequencies for List 2 was only
.57 , whereas in Condition New it was .88 . Thus, when items were repeated in a second list, their mean judged frequencies were related to their actual presented frequencies to a lesser degree than in the case in which Ss were judging frequencies of new items in a second list.

As an alternative to the notion of independence, suppose that the situational frequencies of words presented in two successive lists (Conditions Same and Reverse) combine in a simple additive manner. This would lead to the prediction of a high correlation between the combined List 1 and List 2 frequencies for an item and the mean judged frequency for that item on List 2. In fact, this correlation was .72. It might be argued, though, that this correlation is an overestimation of the true relationship because the combined frequencies must, obviously, include the List 2 presentation frequencies with which List 2 judgments are known to be correlated. To estimate the independent effect of the combined List 1 plus List 2 situational frequencies on List 2 judgments, the influence of List 2 frequencies was partialed out of this correlation. The resulting correlation of List 2 judgments of frequency with List 1 plus List 2 situational frequencies combined. controlling for List 2 presented frequencies, was still .58, as high a correlation as that between the judged frequencies and the actual presented frequencies on List 2.

An alternate way to evaluate this problem is to examine the correlation between List 2 judgments of frequency and the other component of the combined situational frequencies. namely, presented frequencies of occurrence in List 1 for Conditions Same and Reverse. As a result of the method used to construct the two lists, the actual correlation between presented frequencies on List 1 and presented frequencies on List 2 was -.33 . The average correlation. however. between presented frequencies on List 1 and judged frequencies on List 2 was .20 , which was significantly different from -.33 $(p<.01)$. Again, it appears that List 1 presented frequencies exerted an influence on List 2 judgments.

At this point, the data appear to lend strong support 
to the conclusion that List 2 judgments of frequency were determined primarily by List 2 presentation frequencies in Condition New. In Conditions Same and Reverse, though. List 2 frequency judgments seem to have been as strongly related to a combination of List 1 plus List 2 frequencies as they were to List 2 presentation frequencies alone.

Finally, consideration was given to the recall of List 1 frequencies. The average correlation between List 1 presented frequencies and the scaled recall of frequencies was .76 for Conditions Same and Reverse and .81 for Condition New. (The decrease in the correlations from .84 and .87 noted for List 1 performances. respectively, may reflect the nonspecific interference referred to earlier.)

To determine whether these judgments were influenced by the combined frequencies of occurrence in List 1 plus List 2. those combined frequencies were correlated with List 1 recalled frequencies for Conditions Same and Reverse. The average correlation was $.39(p<.05)$. but when the influence of the presented frequencies from List 1 was partialed out the resulting correlation was only -.10 . This suggests that the recall of List 1 frequencies was not intluenced by the combined situational frequencies accrued from List 1 plus List 2.

It is to be remembered that the presented frequencies of items in List 1 correlated -.33 with the presented frequencies of items in List 2. In a manner analogous to the treatment given the List 2 judgments. scaled frequencies of recall of List 1 were correlated with presented frequencies on List 2 for Conditions Same and Reverse. The resulting correlation was -.32 . which again suggests no influence of List 2 presentations on the recall of List 1 frequencies.

\section{DISCUSSION}

The results of the present experiment indicate that when Ss are presented with two immediately successive lists in which items from the first list are repeated with different frequencies in the second list. the Ss are less able to discriminate among different frequencies in the second list than they are to recall the different frequencies from the first list. The fact that $S s$ can recall List 1 frequencies even though the same items were repeated in the second list can be taken as support for the multiple-trace hypothesis. which states that situational frequencies for an item can be differentiated on the basis of time tags. The loss of discrimination among frequencies in List 2. however. indicates that effective time tags may not have been established when the second list was presented immediately after the first. These findings lead one to question the applicability of the multiple-trace hypothesis to situations like those in verbal-discrimination reversal transfer tusks in which second-list lianning inmediately follows first-list learning

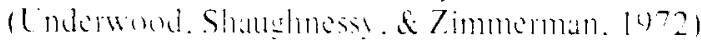

The present findings are not in complete accord with those of Hintzman and Block (1971). who concluded that both List 1 and List 2 frequency judgments. to a great extent, were independent of each other. Any of a number of procedural differences between the two studies may be responsible for the differences in the findings. First, in the Hintzman and Block study. frequency judgments were made after the presentation of both lists. and both judgments for a given word were made at the same time. Next, and possibly most critically, only two frequencies of presentation ( 2 and 5 ) were used for almost all of the items in each of the lists in the Hintzman and Block study. (Other items either were not presented or were presented only once as fillers.) Ss, therefore, may have been able to categorize the items in each list into high and low frequencies. something which would not have been possible in the present study. Such a categorization strategy may have been somewhat unlikely even in the Hintzman and Block experiment, however. since Ss were not instructed as to the nature of the memory test until after both lists were presented. It may even be possible that the presence or absence of the interdependence of situational frequencies for a given item is contingent upon whether the frequency task is an intentional or an incidental learning task. In the present experiment. Ss were told that a frequency-judging task would follow list presentation, while those in the Hintzman and Block study were not instructed as to the nature of the test at the time of list presentation. Finally. the interval between the presentation of the two lists in the Hintzman and Block experiment was filled with a nonverbal task. while in the present study only the frequency-judging task separated the two lists. As such. the "time tags" Hintzman and Block speak of may have been more firmly established in their experiment than was the case here.

Although it seems that the multiple-trace hypothesis cannot completely account for the present data. especially the relative loss of frequency discrimination in List 2. it is also clear that a single-trace position would be hard pressed to account for the findings regarding the recall of List 1 frequencies. In fact. it is not apparent at this time how any position would be able to explain the complex finding that. when words were presented in two lists with different frequencies. recall of List 1 judgments was relatively independent of List 2 frequencies but List 2 judgments were influenced by List 1 frequencies.

\section{REFERENCES}

Ekstrand. B. R., Wallace. W. P.. \& Lnderwood. B. I. A frequens! theory of lerbal-discrimination karning. Psychological Review. 1966. 73.566-578.

Hintzman. D. L. Apparent frequeney as a function of frequem! and the pacing of repetitions. Joumal of Exprimental Puchologe 1969. Sol 139-145

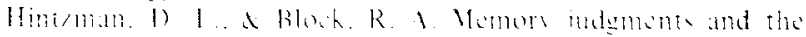


effects of spacing. Journal of Verbal Learning \& Verbal Behavior. 1970. 9.561-566.

Hintzman. D. L.. \& Block. R. A. Repetition and memory: Evidence for a multiple-trace hypothesis. Journal of Experimental Psychology. 1971. 88, 297-306.

Leicht. K. L. Recall and judged frequency of implicitly occurring words. Journal of Verbal Learning \& Verbal Behavior, 1968 , 7. 918-923.

Shaughnessy. J. J., \& Underwood. B. J. The retention of frequency information for categorized lists. Journal of Verbal Learning \& Verbal Behavior, 1973, in press.

Underwood. B. J., \& Freund, J. S. Errors in recognition learning and retention. Journal of Experimental Psychology, 1968, 78 , $55-63$.
Underwood. B. J.. Shaughnessy. J. J., \& Zimmerman, J. List length and method of presentation in verbal discrimination learning with further evidence on retroaction. Journal of Experimental Psychology, 1972, 93, 181-187.

Underwood. B. J.. Zimmerman, J., \& Freund, J. S. Retention of frequency information with observations on recognition and recall. Journal of Experimental Psychology, 1971. 87, 149.162.

(Received for publication October 11. 1972; revision received November 28,1972 .) 